\section{(6) OPEN ACCESS}

\title{
Behavioural, educational and respiratory outcomes of antenatal betamethasone for term caesarean section (ASTECS trial)
}

\author{
Peter Roy Stutchfield, ${ }_{1}^{1}$ Rhiannon Whitaker, ${ }^{2}$ Angela E Gliddon, ${ }^{2}$ Lucie Hobson, ${ }^{3}$ \\ Sailesh Kotecha, ${ }^{4}$ Iolo J M Doull ${ }^{5}$
}

${ }^{1}$ Department of Paediatrics, Betsi Cadwaladr University Health Board, Glan Clwyd Hospital, Rhyl, UK ${ }^{2}$ NWORTH CTU, Bangor University, Bangor, UK ${ }^{3}$ NISCHR CRC, Rhyl, UK ${ }^{4}$ Department of Child Health, Cardiff University School of Medicine, Cardiff, UK ${ }^{5}$ Department of Paediatric Respiratory Medicine, Children's Hospital for Wales, Cardiff, UK

\section{Correspondence to} Dr Peter Roy Stutchfield, Department of Paediatrics, Betsi Cadwaladr University Health Board, Glan Clwyd Hospital, Rhyl, Denbighshire, LL18 5UJ, UK: pstutch30@gmail.com

Received 5 October 2012 Accepted 17 January 2013 Published Online First 19 February 2013

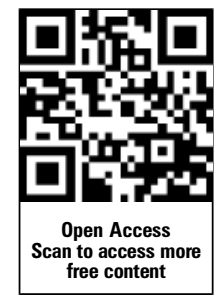

To cite: Stutchfield $P R$, Whitaker R, Gliddon AE, et al. Arch Dis Child Fetal Neonatal Ed 2013;98: F195-F200.

\section{ABSTRACT}

Objectives To determine whether antenatal betamethasone prior to elective term caesarean section (CS) affects long term behavioural, cognitive or developmental outcome, and whether the risk of asthma or atopic disease is reduced.

Design A questionnaire based follow-up of a multicentre randomised controlled trial (Antenatal Steroids for Term Elective Caesarean Section, BMJ 2005). Setting Four UK study centres from the original trial. Participants 862 participants from the four largest recruiting centres, $92 \%$ of the original study. 824 (96\%) were traced and 799 (93\%) were successfully contacted. Fifty-one percent (407/799) completed and returned the questionnaire. The children were aged 8-15 years (median 12.2 years, $52 \%$ girls). 386 gave consent to contact schools with 352 (91\%) reports received. Main outcome measures Questionnaires including a strengths and difficulties questionnaire, International Study of Asthma and Allergies in Childhood, general health and school performance.

Results There were no significant differences between children whose mothers received betamethasone and controls for the mean total strengths and difficulties questionnaire scores and subscores for hyperactivity, emotional symptoms, prosocial behaviour, conduct or peer problems. $25(12 \%)$ children whose mothers received betamethasone had reported learning difficulties compared with $27(14 \%)$ control children. The proportion of children who achieved standard assessment tests KS2 exams level 4 or above for mathematics, English or science was similar as were the rates of ever reported wheeze (30\% vs $30 \%$ ), asthma ( $24 \%$ vs $21 \%$ ), eczema (34\% vs $37 \%$ ) and hay fever (25\% vs $27 \%$ ).

Conclusions Antenatal betamethasone did not result in any adverse outcomes or reduction in asthma or atopy. It should be considered for elective CS at 37-38 weeks of gestation.

Trial registration: Original trial was preregistration, the trial publication is BMJ. 2005 Sep 24;331 (7518):662.

\section{INTRODUCTION}

Birth by caesarean section (CS) in westernised countries has increased significantly over the last three decades ${ }^{1}$ increasing from $16 \%$ in 1995 to 25\% in 2007 in the UK, ${ }^{2}{ }^{3}$ and from 20\% in 1996 to $31 \%$ in 2006 in the USA. ${ }^{4}$ However elective CS at term is associated with significant neonatal morbidity $^{5-7}$ respiratory distress syndrome (RDS), transient tachypnoea of the newborn (TTN), need for

\section{What is already known on this topic}

Antenatal betamethasone reduces respiratory morbidity in term babies delivered by elective caesarean section by $50 \%$.

- A single course of antenatal steroid has no adverse effect on subsequent physical growth and neurological or cognitive development of babies born before 34 weeks gestation.

- Antenatal steroids lead to upregulation of pulmonary epithelial sodium channel genes with a switch from lung fluid secretion to fluid absorption and increased surfactant production.

\section{What this study adds}

No adverse effect was seen on health, behaviour and academic achievement of children born following a single course of antenatal betamethasone at term.

- Antenatal betamethasone did not reduce the prevalence of asthma and allergy following elective caesarean section.

mechanical ventilation ${ }^{8}$ and longer term conditions including 20\% increased risk of asthma, ${ }^{9}$ type 1 diabetes mellitus, ${ }^{10}$ with a twofold increased risk of atopy. $^{11}$

The well-established benefits of antenatal corticosteroids prompted the Antenatal Steroids for Term Elective Caesarean Section (ASTECS) study ${ }^{12}$ which demonstrated decreased risk of TTN $(0.040$ vs 0.021 ; relative risk (RR) $0.54,95 \%$ CI 0.26 to 1.12 ) and RDS (0.011 vs 0.002 ; RR $0.21,95 \%$ CI 0.03 to 1.32 ). The predicted probability of admission to a neonatal unit with respiratory distress at 37 weeks was $11.4 \%$ in the control group and $5.2 \%$ in the treatment group, at 38 weeks $6.2 \%$ and $2.8 \%$, and at 39 weeks $1.5 \%$ and $0.6 \%$, respectively, confirming a $50 \%$ reduction in respiratory morbidity up to 39 weeks gestation.

Concerns have been raised about the potential long term effects of administering exogenous steroids before elective CS. ${ }^{13}$ A Cochrane review ${ }^{14}$ and the evidence based guideline of the Royal College of Obstetricians and Gynaecologists ${ }^{15}$ concluded that a single course of antenatal steroid has no 
adverse effect on subsequent physical growth and neurological or cognitive development. In contrast, repeated courses of antenatal or postnatal steroids to facilitate extubation from mechanical ventilation show conflicting results with reported increases in cerebral palsy and behavioural changes. ${ }^{16-18}$

We hypothesised that the short course of antenatal steroids administered prior to an elective CS would not result in long term neurological or cognitive development effects, but might, through the decreased risk of RDS and TTN, decrease the risk of development of asthma and atopic diseases.

\section{METHODS}

ASTECS was a randomised open label trial of two intramuscular doses of $12 \mathrm{mg}$ betamethasone separated by $24 \mathrm{~h}$ within $48 \mathrm{~h}$ of delivery, compared with usual treatment without antenatal steroids in pregnant women undergoing elective CS at term. ASTECS was conducted between 1995 and 2002. ASTECS-2 is a follow-up study of the children aged 8-15 years. No studies have been reported using antenatal steroids at term. ${ }^{19}$

\section{Participants}

Of the 998 women entered into ASTECS, logistical considerations dictated that we restrict the follow-up study ASTECS-2 to those delivered at the four largest recruiting centres. Tracing was performed using information from the original study, local child health registers and the National Health Service (NHS) demographic tracking system. Ethics approval was obtained from South East Wales Research Ethics Committee.

\section{Study procedures}

Participants were sent study information including questionnaires and consent forms and asked for permission to contact their schools. Study numbers and return rates are shown in the CONSORT diagram, figure 1 . The original trial blinded allocation was reused in the current study.

\section{Study instruments}

The questionnaire was based on the International Study of Asthma and Allergies in Childhood ${ }^{20}$ and supplemented with further questions on the child's medical history, hospital admissions, attainment in school key stages 1 and 2 national standard assessment tests (SATs) and the child's strengths and difficulties questionnaire (SDQ) which consists of 25 questions providing measures in five dimensions-hyperactivity, emotional symptoms, conduct problems, peer problems and prosocial behaviour. ${ }^{21}$ The four difficulties scores are combined to create the total SDQ score. Normal total SDQ scores lie between 0 and 13, borderline between 14 and 16 and abnormal $17+$. As we were investigating the potential negative effects of betamethasone, a one-sided test was applied to each of these subscales and the total difficulties score. The school was asked to confirm SATs key stages 1 and 2 results and to give data on general progress, behavioural characteristics and special educational needs.

\section{Statistical analysis}

The principal analyses are descriptive and one-sided tests were used $\left(\chi^{2}\right.$ tests for categorical comparisons and either $t$-tests or Mann Whitney tests for scale variables) with 5\% significance reported.

\section{RESULTS}

\section{Recruitment}

We followed up all 862 participants from the four largest recruiting centres, $92 \%$ of 942 of the original study from 10 centres (figure 1), and 824 (96\%) were traced-25 communications were returned as 'unknown at this address'. Of 799 successfully contacted, 51\% (407) returned the completed questionnaires. The children were aged 8-15 years with a median age of 12.2 years of which $52 \%$ were girls. Of the 407 recruited, 386 parents consented to contacting schools, and responses were received for 352 children (figure 2).

\section{Sample characteristics}

Representativeness of the four centres sampled

The 942 mothers in the original study had a mean age of 30.8 (SD $\pm 5.2)$ years, $199(21 \%)$ reported being smokers and $102(11 \%)$ reported asthma. The babies had a mean gestation of 269 (SD \pm 6.6 ) days and birth weight of 3290 ( $\mathrm{SD} \pm 470$ ) g. Of these babies
Figure 1 CONSORT diagram showing recruitment of mothers and return rates of their questionnaires in the Antenatal Steroids for Term Elective Caesarean Section (ASTECS)-2 study.

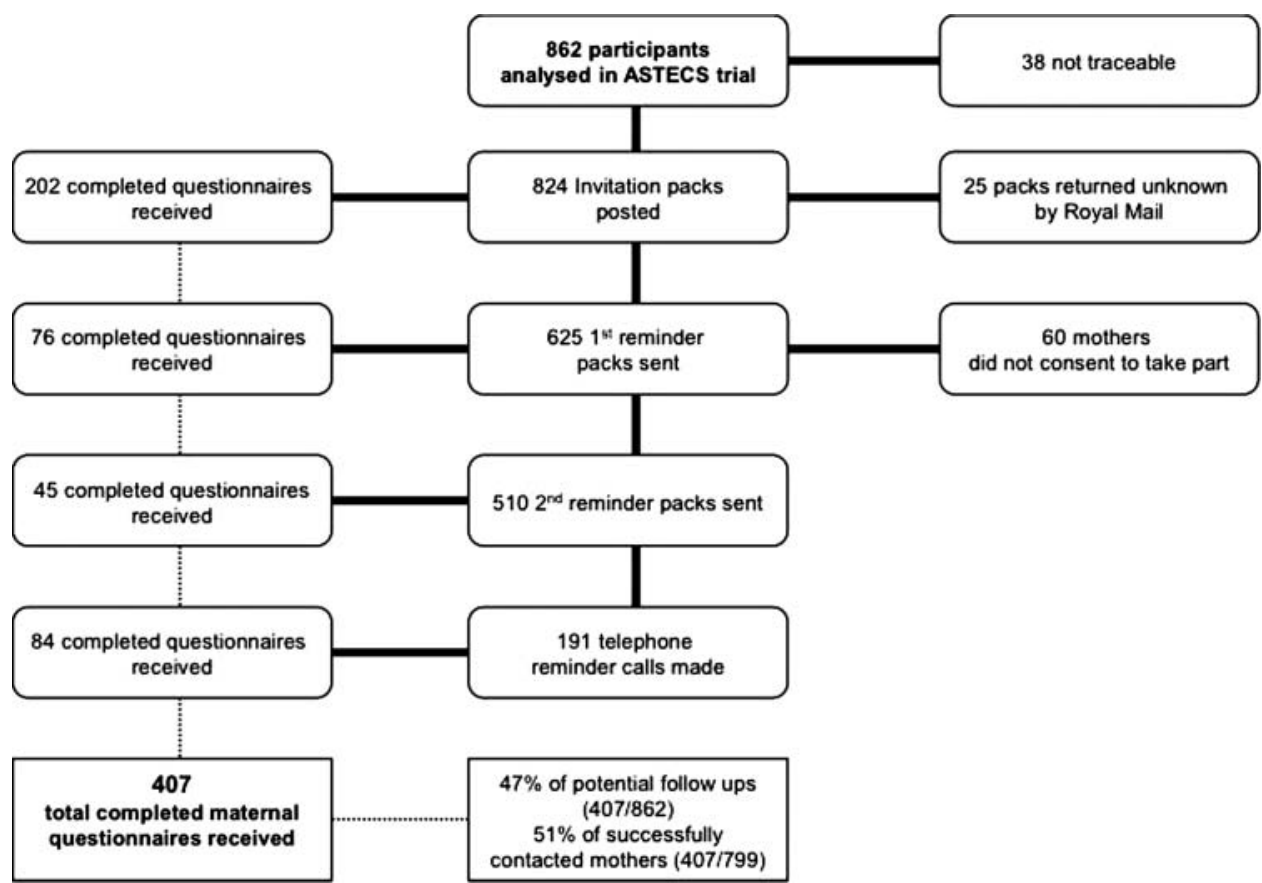




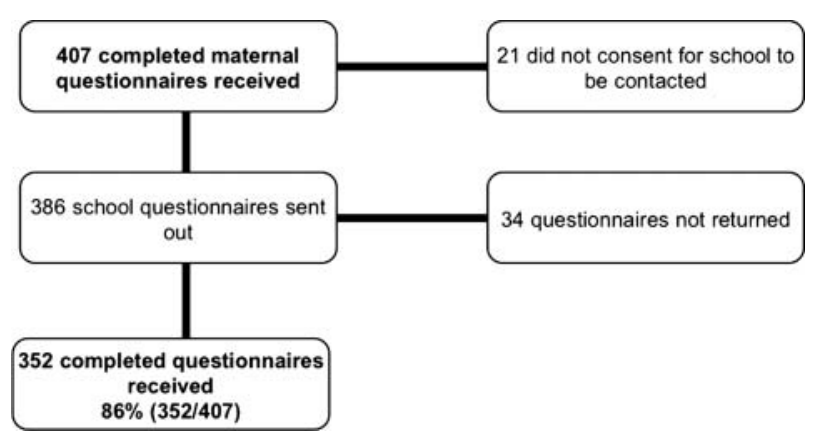

Figure 2 CONSORT diagram showing recruitment of schools and return rates of their questionnaires in the Antenatal Steroids for Term Elective Caesarean Section-2 study.

$58(6 \%)$ were admitted to the special care baby unit (SCBU) with 35 (4\%) having respiratory difficulties. A comparison with the sample drawn from the four centres included in ASTECS-2 revealed no significant differences in either maternal or child characteristics except that the centres that were followed up admitted a smaller proportion of babies (6\%) to SCBU than the centres that were not followed up $(13 \%)(p=0.01)$.

Representativeness of responders to the study

Study respondents were slightly older $(31.9(\mathrm{SD} \pm 4.9)$ years vs $29.7(\mathrm{SD} \pm 5.2)$ years, $\mathrm{p}<0.01)$, more likely to have been nonsmokers $(84 \%$ vs $75 \%, \mathrm{p}<0.01)$ and more likely to have had a baby admitted to SCBU ( $7 \%$ vs $4 \%, p=0.06)$ than nonrespondents. Rates of asthma, emergency CS, gestational age and birth weight were similar. Infants of respondent mothers were more likely to have been admitted to SCBU with respiratory difficulties than those whose mothers did not respond $(5 \%$ vs $2 \%, \mathrm{p}=0.01)$.

\section{Comparison of treatment and control demographic data}

Table 1 gives the original ASTECS demographics for the respondents, comparing the betamethasone and control groups. Both groups had similar participant (mother) demographic profile and the babies had similar birth weights and gestational ages. As in the original ASTECS study, ASTECS-2 control group respondents had a higher proportion of children admitted to SCBU (21 (11\%) compared with 8 (4\%) in the treatment group, $\mathrm{p}<0.01)$ with a higher proportion of children admitted to SCBU with respiratory distress, (17 (9\%) compared with $5(2 \%)$ in the treatment group, $\mathrm{p}<0.01$ ).

\section{Study outcomes}

Behaviour

The mean SDQ scores for the strengths and difficulties subscales were similar in both groups (table 2). None of the differences reached statistical significance. There were no significant differences between the two groups in the proportion of children requiring additional help in school, $34(18 \%)$ of those mothers who received betamethasone compared with 22 (13.3\%) controls $\chi^{2}(1)=1.49, p=0.22$ who did not.

Of the 407 children followed up, 305 were 11 years or older and would have received a KS2 level evaluation; schools reported data for $266(87 \%)$ children. There were no significant differences between groups in the levels attained at KS2 with $88 \%$ achieving level 4 or above in mathematics in the control group versus $86 \%$ in the betamethasone group, in science $94 \%$ in the control group

Table 1 Summary of characteristics for the participants and the children's demographics by treatment group

\begin{tabular}{|c|c|c|c|c|}
\hline $\mathrm{N}$ & $\begin{array}{l}\text { Control } \\
190\end{array}$ & $\begin{array}{l}\text { Betamethasone } \\
217\end{array}$ & Test statistic & Significance \\
\hline \multicolumn{5}{|l|}{ Age of mother recorded at randomization } \\
\hline Range & $18.4-46.4$ & $19.3-43.1$ & & \\
\hline Mean (SD) & $31.5(5.0)$ & $32.3(4.7)$ & $\mathrm{t}(405)=1.68$ & 0.09 \\
\hline Median (IQR) & $31.4(28.2-34.5)$ & $32.3(29.7-35.1)$ & & \\
\hline Mother has asthma during pregnancy $\mathrm{n}(\%)$ & $22(12)$ & $17(8)$ & $\chi^{2}(1)=1.64$ & 0.20 \\
\hline Mother is a smoker $\mathrm{n}(\%)$ & $37(20)$ & $30(14)$ & $\chi^{2}(1)=2.35$ & 0.13 \\
\hline Emergency caesarean section $\mathrm{n}(\%)$ & $9(5)$ & $16(7)$ & $\chi^{2}(1)=1.22$ & 0.27 \\
\hline \multicolumn{5}{|l|}{ Gestational age (weeks) } \\
\hline Range & $35.9-42.0$ & $35.7-41.0$ & & \\
\hline Mean (SD) & $38.4(1.0)$ & $38.5(0.9)$ & $\mathrm{t}(405)=0.99$ & 0.32 \\
\hline Median (IQR) & $38.4(38.0-39.0)$ & $38.6(38.0-39.0)$ & & \\
\hline \multicolumn{5}{|l|}{ Birth weight $(\mathrm{kg})$} \\
\hline Range & $2.06-4.66$ & $1.62-4.58$ & & \\
\hline Mean (SD) & $3.34(0.49)$ & $3.27(0.46)$ & $\mathrm{t}(403)=-1.55$ & 0.12 \\
\hline Median (IQR) & $3.38(3.02-3.66)$ & $3.22(2.99-3.58)$ & & \\
\hline \multicolumn{5}{|l|}{ Gender of child $n(\%)$} \\
\hline Female & $100(53)$ & $112(52)$ & & \\
\hline Male & $90(47)$ & $105(48)$ & $\chi^{2}(1)=0.04$ & 0.84 \\
\hline Baby admitted to SCBU n (\%) & $21(11)$ & $8(4)$ & $\chi^{2}(1)=8.30$ & $<0.01 *$ \\
\hline Admitted to SCBU with respiratory distress $n(\%)$ & $17(9)$ & $5(2)$ & $\chi^{2}(1)=8.74$ & $<0.01^{*}$ \\
\hline \multicolumn{5}{|l|}{ Centre $\mathrm{n}(\%)$} \\
\hline Bradford & $65(34)$ & $69(32)$ & & \\
\hline Glan Clwyd & $46(24)$ & $55(25)$ & & \\
\hline Ipswich & $45(24)$ & $57(26)$ & & \\
\hline Southmead & $34(18)$ & $36(17)$ & $\chi^{2}(3)=0.60$ & 0.90 \\
\hline
\end{tabular}


Table 2 Summary of scores for the strengths and difficulties subscales for the participants by treatment group and school assessment of additional help and quartile of ability

\begin{tabular}{|c|c|c|c|c|}
\hline Outcome measure: mean (SD) & $\begin{array}{l}\text { Control } \\
\mathrm{N}=190\end{array}$ & $\begin{array}{l}\text { Betamethasone } \\
\mathrm{N}=217\end{array}$ & Difference $(95 \% \mathrm{CI})$ & Significance \\
\hline Hyperactivity scale & $3.06(2.74)$ & $3.32(2.85)$ & $0.26(-0.29$ to 0.81$)$ & 0.19 \\
\hline Emotional symptoms scale & $1.98(2.28)$ & $2.05(2.33)$ & $0.07(-0.38$ to 0.52$)$ & 0.40 \\
\hline Conduct problems scale & $1.34(1.59)$ & $1.31(1.72)$ & $-0.03(-0.36$ to 0.29$)$ & 0.80 \\
\hline Peer problems scale & $1.47(1.88)$ & $1.36(1.91)$ & $-0.11(-0.48$ to 0.26$)$ & 0.87 \\
\hline Total difficulties score & $7.85(6.49)$ & $8.03(6.83)$ & $0.18(-1.12$ to 1.48$)$ & 0.19 \\
\hline Prosocial scale & $8.58(1.66)$ & $8.72(1.76)$ & $0.14(-0.19$ to 0.48$)$ & 0.90 \\
\hline \multirow[t]{2}{*}{ Additional help required $\mathrm{n}(\%)$} & $N=166$ & $\mathrm{~N}=189$ & & \\
\hline & $22(13.3)$ & $34(18.0)$ & $\chi^{2}(1)=1.492$ & 0.22 \\
\hline School assessment of child's quartile of ability & $\mathrm{N}=164$ & $\mathrm{~N}=186$ & & \\
\hline Top quarter of academic ability & $74(45.1)$ & 70 (37.6) & & \\
\hline Middle half of academic ability & $76(46.3)$ & $83(44.6)$ & $\chi^{2}(2)=6.74$ & 0.03 \\
\hline Lower quarter of academic ability & $14(8.5)$ & $33(17.7 \%)$ & & \\
\hline
\end{tabular}

versus 91\% in the betamethasone group and in English 93\% in the control group versus $87 \%$ in the betamethasone group. KS1 school reports were received for 74 of the 102 children who were too young to have a KS2 assessment. There were no significant differences noted in the number of children reaching levels 2 or 3 between betamethasone and control children. Schools were asked to report which quartile of ability they perceived each child to be in. The difference between the groups did reach significance. Twenty-five (12\%) children whose mothers received betamethasone had reported learning difficulties compared with 27 (14\%) control children. Dyslexia was the most common learning difficulty reported followed by attention deficit disorder (ADHD) (nine controls and seven treatment children with dyslexia, four controls and three treatment children with ADHD). Two children in the betamethasone group had severe learning difficulties; one had X linked mental retardation and the other global developmental delay with dysmorphic features. One child in the control group with severe learning difficulties had Down's syndrome. Two children in each arm had Asperger's syndrome and autism was noted in two treatment group and two control group children.

\section{Health}

There were no significant differences between the two groups in any parent reported measures of overall health (table 3 ). Rates of medical problems reported, hospital admissions ever, learning difficulties, movement problems and numbers of children on medications were similar between the two groups. There was no significant difference between the two groups in the rates of asthma, whether measured by wheeze ever, wheeze in the last year, use of inhalers or having asthma, or in reported eczema or hay fever. There was no significant difference in hospital admission rates for respiratory or non-respiratory causes with fewer reported hospitalisations as a result of accidental injury in those whose mothers had received betamethasone. Only one (control) child was diagnosed with diabetes.

We extended our analysis of the results of the parent questionnaire to consider the health of those children who had been admitted to SCBU after birth. As the study is not powered to detect differences in such small numbers of children, we have presented the results in table 4 without applying statistical testing.

\section{DISCUSSION}

We found no difference in behavioural characteristics between children whose mothers received betamethasone and those who did not as determined by the Strengths and Difficulties questionnaire (SDQ). The results of the SATs key stages 1 and 2 demonstrated that the treatment and control populations did not differ in academic achievement, with results comparable with the normal population and within government targets. No children were reported to have cerebral palsy or neurological disability. There was no evidence that general health was adversely affected with no significant difference in the number of children admitted to hospital with infections and accidental injury. Antenatal betamethasone did not affect the number of children who developed asthma or atopic disease.

This is the first published study to assess the long-term outcome for children whose mothers received a single course of betamethasone antenatally before elective CS at term. For logistical reasons only children whose mothers were recruited at the four main centres were identified for the follow-up study. ${ }^{12}$ Demographic data of these mothers and children was comparable with that of the whole group.

A primary strength of this study was the children were more than 8 years old-an age when physical, behavioural and learning difficulties are more likely to be evident. There are a number of limitations, however. Although we achieved a 51\% response rate to those who were traced, the total number of children in the control and betamethasone groups (190 vs 217$)$ is small. With the time delay between the initial recruitment to the ASTECS study and the start of the follow-up study, ASTECS-2, not all mothers could be traced. Mothers who had no recollection of the ASTECS trial, predominantly from the control group, were less likely to respond to the initial letter potentially leading to bias. Follow-up phone calls of all who did not respond allowed the study to be discussed with an effective increase in recruitment. The trial allocation remained blinded throughout the process.

Responses to the questionnaires depended on the mothers' recall and assessment. We did not refer to general practitioner or hospital records and teachers were not asked to complete SDQ questionnaires. However large community studies suggest that parents and teachers provide information of roughly equal predictive value. Behaviour determined through the SDQ has been well validated, ${ }^{22}$ and there was no difference between the two groups although slightly more children in the betamethasone group had scores in the abnormal range for hyperactivity and emotional symptoms. This may indicate a difference in behaviour but comes from only one source of information. The SDQ is a screening tool to identify those at increased risk but 
Table 3 Description of the child's childhood medical problems

\begin{tabular}{|c|c|c|c|c|}
\hline Parent report n (\%) & $\begin{array}{l}\text { Control } \\
\mathrm{N}=190\end{array}$ & $\begin{array}{l}\text { Betamethasone } \\
\mathrm{N}=217\end{array}$ & $\chi^{2}(1)$ & Significance \\
\hline Child has medical problems & $68(36)$ & $77(36)$ & 0.01 & 0.95 \\
\hline $\begin{array}{l}\text { Child has problems with } \\
\text { movement }\end{array}$ & $6(3)$ & $10(5)$ & 0.56 & 0.45 \\
\hline $\begin{array}{l}\text { Child has been diagnosed } \\
\text { with a condition }\end{array}$ & $51(27)$ & $56(26)$ & 0.04 & 0.83 \\
\hline Child is on medication & $46(24)$ & $41(19)$ & 1.70 & 0.19 \\
\hline $\begin{array}{l}\text { Child ever admitted to } \\
\text { hospital }\end{array}$ & $96(51)$ & $98(45)$ & 1.17 & 0.28 \\
\hline $\begin{array}{l}\text { Child ever wheezed or had } \\
\text { whistling in the chest }\end{array}$ & $56(30)$ & $66(30)$ & 0.04 & 0.84 \\
\hline $\begin{array}{l}\text { Of these, child wheezed or } \\
\text { had whistling in the chest } \\
\text { in the past year }\end{array}$ & 22 & 31 & & \\
\hline Has the child ever had asthma & $40(21)$ & $53(24)$ & 0.65 & 0.42 \\
\hline $\begin{array}{l}\text { In the last year, has the child } \\
\text { used any asthma inhalers or } \\
\text { medicines }\end{array}$ & $24(13)$ & $31(14)$ & 0.24 & 0.63 \\
\hline $\begin{array}{l}\text { Has the child ever had a } \\
\text { problem with sneezing or a } \\
\text { runny/blocked nose when they } \\
\text { did not have a cold }\end{array}$ & $60(32)$ & $51(24)$ & 3.33 & 0.07 \\
\hline $\begin{array}{l}\text { Of these, in the last year } \\
\text { has this nose problem been } \\
\text { accompanied by } \\
\text { itchy-watering eyes }\end{array}$ & 35 & 41 & & \\
\hline $\begin{array}{l}\text { Has the child ever had hay } \\
\text { fever }\end{array}$ & $51(27)$ & $54(25)$ & 0.20 & 0.65 \\
\hline $\begin{array}{l}\text { Has the child ever taken any } \\
\text { regular nasal sprays or } \\
\text { medicines }\end{array}$ & $42(22)$ & $38(18)$ & 1.35 & 0.25 \\
\hline $\begin{array}{l}\text { Has the child had an itchy } \\
\text { rash which was coming and } \\
\text { going for at least } 6 \text { months }\end{array}$ & $30(16)$ & $30(14)$ & 0.31 & 0.58 \\
\hline $\begin{array}{l}\text { Of these, has the child had } \\
\text { this itchy rash at any times } \\
\text { in the last year }\end{array}$ & 25 & 24 & & \\
\hline $\begin{array}{l}\text { Of these, has this itchy } \\
\text { rash at any time affected: } \\
\text { folds of the elbows, behind } \\
\text { the knees, in front of the } \\
\text { ankles, under the buttocks, } \\
\text { around the neck ears or } \\
\text { eyes }\end{array}$ & 21 & 22 & & \\
\hline $\begin{array}{l}\text { Has the child ever had } \\
\text { eczema }\end{array}$ & $70(37)$ & $73(34)$ & 0.46 & 0.50 \\
\hline $\begin{array}{l}\text { Has your child ever taken any } \\
\text { creams or medicines for } \\
\text { eczema }\end{array}$ & 65 (34) & $70(32)$ & 0.15 & 0.70 \\
\hline \multicolumn{5}{|c|}{ Reported reasons for admission to hospital } \\
\hline Respiratory infection & $20(11)$ & $15(7)$ & & \\
\hline Non-respiratory infection & $24(13)$ & $20(9)$ & & \\
\hline Accidental injury & $17(9)$ & $14(6)$ & & \\
\hline Surgery & $24(13)$ & 31 (14) & & \\
\hline Asthma & $1(1)$ & $6(3)$ & & \\
\hline
\end{tabular}

clinical assessment, teacher's reports and psychological testing are necessary to identify a problem. Normative SDQ data for Britain from 10438 children 5-15 years old shows $16 \%$ of $5-10$ years old and $12.9 \%$ of $11-15$ years old children had a hyperactivity health score in the abnormal range. ${ }^{23}$ For the emotional health symptoms score the corresponding figures are $10.6 \%$ and $12.2 \%$, respectively. There were more children reported to have $\mathrm{ADHD}$, dyslexia and autism in the control group.
Table 4 The children's reported medical problems; those admitted to SCBU

\begin{tabular}{|c|c|c|}
\hline Parent report n (\%) & $\begin{array}{l}\text { Control } \\
\mathrm{N}=21\end{array}$ & $\begin{array}{l}\text { Betamethasone } \\
\mathrm{N}=8\end{array}$ \\
\hline Child ever wheezed or had whistling in the chest & $9(43)$ & $2(25)$ \\
\hline Has the child ever had asthma & $6(29)$ & $2(25)$ \\
\hline $\begin{array}{l}\text { In the last year, has the child used any asthma } \\
\text { inhalers or medicines }\end{array}$ & $7(33)$ & $2(25)$ \\
\hline $\begin{array}{l}\text { Has the child ever had a problem with sneezing or a } \\
\text { runny/blocked nose when they did not have a cold }\end{array}$ & $11(52)$ & $0(0)$ \\
\hline Has the child ever had hay fever & $9(43)$ & $2(25)$ \\
\hline $\begin{array}{l}\text { Has the child ever taken any regular nasal sprays or } \\
\text { medicines }\end{array}$ & $8(38)$ & $2(25)$ \\
\hline $\begin{array}{l}\text { Has the child had an itchy rash which was coming } \\
\text { and going for at least } 6 \text { months }\end{array}$ & $5(24)$ & $1(13)$ \\
\hline Has the child ever had eczema & $9(43)$ & $3(38)$ \\
\hline $\begin{array}{l}\text { Has the child ever taken any creams or medicines } \\
\text { for eczema }\end{array}$ & $9(43)$ & $2(25)$ \\
\hline
\end{tabular}

Academic progress, including details of learning difficulties requiring additional support, was substantiated by the questionnaire to the schools. However not all mothers or young people agreed to the school being contacted, potentially introducing bias, although this could affect both groups. We obtained information on key stages 1 and 2 SATs for those attending schools in England. SATs were abolished for pupils resident in Wales in 2004 with the grade achieved derived by teacher assessment. The difference between the school assessments recorded in quartiles of academic ability, appeared a discordant finding. Ideally standardised, age-appropriate, cognitive and psychological assessments would have been undertaken on all in the follow-up study but this was not possible.

Follow-up studies reporting outcome up to 31 years after a single course of antenatal steroid given to mothers delivering before 34 weeks gestation have not shown adverse effect on physical growth and neurological or cognitive development. ${ }^{14} \quad 1524$ However outcome studies following repeated courses of antenatal steroids from 24 weeks gestation, or high doses used postnatally to reduce chronic lung disease, have shown conflicting results with increase in cerebral palsy and behavioural changes reported. ${ }^{16-}$ 1825 With three or more courses of antenatal steroid, an increase in rates of aggressive/destructive, distractible, and hyperkinetic behaviour at 3 years and 6 years are reported. ${ }^{25}$ The current evidence suggests that the very immature brain is vulnerable when exposed to high doses of corticosteroid for prolonged periods either antenatally or postnatally. As with the preterm infant, our findings suggest that there were no adverse consequences of a single course of antenatal betamethasone at term gestation.

Dalziel et al reported no difference in lung function at 30 years between 181 betamethasone-exposed and 202 placebo-exposed participants whose mothers were randomised at 24-36 weeks gestation to receive a single course betamethasone. ${ }^{26}$ The prevalence of asthma, eczema and hay fever was similar between groups, and comparable with the International Study of Asthma and Allergies in Childhood phase 3 studies conducted between 1999 and 2004. ${ }^{27}$ Our findings suggest that antenatal steroids do not significantly affect the rate of development of atopic disease.

Our follow-up study has provided no reason to change our original recommendations that delivery by elective CS should be delayed until the 39th week wherever possible to reduce the risk of respiratory morbidity. ${ }^{12}$ When it is necessary to deliver 
by prelabour CS at 37 weeks or 38 weeks, parents can be reassured that the administration of a single course of antenatal betamethasone is not only beneficial in the short term, but does not have any adverse long term consequences.

Acknowledgements The authors would like to thank Kirsty Macguire, Darren Baker, Huw Roberts, Debbie Skelhorn, Sarah Evans, Sarah Kotecha, Professor Ben Shaw, Dr Jim Turner, Haydn and Rachel Sigsworth, Dr Mathew Ellis, Phil Shrimpton, Dr Jonathan Cox, Lesley Poole, Dr Eduardo Moya, Barry Clarke and Richard Walker for their contributions to the smooth running and success of the research. Special thanks are due to all the parents and schools who took time and responded to the questionnaires.

Contributors All authors contributed to the design of the protocol and have contributed to, read and commented upon successive drafts of this paper. Additionally: PRS is the consultant paediatrician and neonatologist who developed the protocol, and initiated and coordinated the original ASTEC trial. He contacted local Principle Investigator and arranged contact details through local child health managers. He contacted mothers and schools to aid recruitment, supervised collection, validation and analysis of data. He is the clinical guarantor. RW was the trial statistician for the original ASTECS study who designed and oversaw the data collection, supervised the ethical submission, developed the analysis plan and analysed this study. She is the statistical guarantor. AEG is the study's manager who submitted the ethical approval, was responsible for trial management and clinical governance, arranged patient representation in the study, assisted with analysis of the data and updated literature searches. LH is the study research nurse who wrote patient information sheets and consent forms, organised distribution of maternal and school questionnaires, coordinated the collection and validation of the data and ensured effective management of the study. SK is a professor of child health who was involved in the development and management of this follow-up study, providing advice and guidance throughout. IJMD is a consultant respiratory paediatrician who was instrumental in the development of the protocol to compare prevalence of asthma. He has been involved in the management of this study, providing advice and guidance.

Funding This study was partially funded by the North Wales Small Grant Committee and Welsh Children and Young People's Research Network (CYPRN).

Competing interests All authors have the support of Betsi Cadwaladr University Health Board for the submitted work but no other competing interest.

Ethics approval South East Wales Research Ethics Committee.

Patient consent Obtained.

Provenance and peer review Commissioned; externally peer reviewed.

Data sharing statement If further information on the original ASTECS study or the current follow-up study is required Dr Peter Stutchfield the Chief Investigator for both studies can be contacted at pstutch30@gmail.com

Open Access This is an Open Access article distributed in accordance with the Creative Commons Attribution Non Commercial (CC BY-NC 3.0) license, which permits others to distribute, remix, adapt, build upon this work non-commercially, and license their derivative works on different terms, provided the original work is properly cited and the use is non-commercial. See: http://creativecommons.org/ licenses/by-nc/3.0/

\section{REFERENCES}

1 Menacker F, Declercq E, Macdorman MF. Cesarean delivery: background, trends, and epidemiology. Semin Perinatol 2006;30:235-41.

2 NHS_Information_Centre. Method of delivery. In: Office_for_National_Statistics, ed 2009.

3 Wales_Assembly_Government. Maternity statistics-method of delivery in Wales. In: Office_for_National_Statistics. ed, 2009.
4 Martin JA, Hamilton BE, Sutton PD, et al. Births: final data for 2007. Natl Vital Stat Rep 2010;58:1-85.

5 Villar J, Carroli G, Zavaleta N, et al. Maternal and neonatal individual risks and benefits associated with caesarean delivery: multicentre prospective study. BMJ 2007; $335: 1025$

6 Hansen AK, Wisborg $K$, Uldbjerg $N$, et al. Risk of respiratory morbidity in term infants delivered by elective caesarean section: cohort study. BMJ 2008;336:85-7.

7 Tita AT, Landon MB, Spong CY, et al. Timing of elective repeat cesarean delivery at term and neonatal outcomes. N Engl J Med 2009;360:111-20.

8 Hansen AK, Wisborg K, Uldbjerg N, et al. Elective caesarean section and respiratory morbidity in the term and near-term neonate. Acta Obstet Gynecol Scand 2007;86:389-94.

9 Thavagnanam S, Fleming J, Bromley A, et al. A meta-analysis of the association between Caesarean section and childhood asthma. Clin Exp Allergy 2008;38:629-33

10 Cardwell CR, Stene LC, Joner G, et al. Caesarean section is associated with an increased risk of childhood-onset type 1 diabetes mellitus: a meta-analysis of observational studies. Diabetologia 2008;51:726-35.

11 Pistiner M, Gold DR, Abdulkerim H, et al. Birth by cesarean section, allergic rhinitis, and allergic sensitization among children with a parental history of atopy. J Allergy Clin Immunol 2008:122:274-9.

12 Stutchfield P, Whitaker R, Russell I. Antenatal betamethasone and incidence of neonatal respiratory distress after elective caesarean section: pragmatic randomised trial. BMJ 2005;331:662

13 Steer PJ, Modi N. Elective caesarean sections — risks to the infant. Lancet 2009;374:675-6.

14 Roberts D, Dalziel S. Antenatal corticosteroids for accelerating fetal lung maturation for women at risk of preterm birth. Cochrane Database Syst Rev 2006;3:CD004454

15 Royal College_of_Obstetricians_\&_Gynaecologists. Antenatal corticosteroids to prevent respiratory distress syndrome Greentop guideline. London: Royal College of Obstetricians and Gynaecologists, 2004.

16 Walfisch A, Hallak M, Mazor M. Multiple courses of antenatal steroids: risks and benefits. Obstet Gynecol 2001;98:491-7.

17 Yeh TF, Lin YJ, Huang CC, et al. Early dexamethasone therapy in preterm infants: a follow-up study. Pediatrics 1998;101:E7

18 Yeh TF, Lin YJ, Lin HC, et al. Outcomes at school age after postnatal dexamethasone therapy for lung disease of prematurity. $N$ Engl J Med 2004:350:1304-13.

19 Sotiriadis A, Makrydimas G, Papatheodorou S, et al. Corticosteroids for preventing neonatal respiratory morbidity after elective caesarean section at term. Cochrane Database Syst Rev 2009:4:CD006614.

20 Asher MI, Weiland SK. The international study of asthma and allergies in childhood (ISAAC). ISAAC steering committee. Clin Exp Allergy 1998;28(Suppl 5):52-66; discussion 90-1.

21 Goodman R. The strengths and difficulties questionnaire: a research note. J Child Psychol Psychiatry 1997;38:581-6.

22 Goodman RFT, Simmons H, Gatward R, et al. Using the strengths and difficulties questionnaire (SDQ) to screen for child psychiatric disorders. Br J Psychiatry 2000;177:534-9.

23 Meltzer H, Gatward R, Goodman R, et al. Mental health of children and adolescents in Great Britain 2000. Int Rev Psychiatry 2003;15:185-7.

24 Dalziel SR, Lim VK, Lambert A, et al. Antenatal exposure to betamethasone: psychological functioning and health related quality of life 31 years after inclusion in randomised controlled trial. BMJ 2005;331:665.

25 French NP, Hagan R, Evans SF, et al. Repeated antenatal corticosteroids: effects on cerebral palsy and childhood behavior. Am J Obstet Gynecol 2004;190:588-95.

26 Dalziel SR, Rea HH, Walker NK, et al. Long term effects of antenatal betamethasone on lung function: 30 year follow up of a randomised controlled trial. Thorax 2006:61:678-83.

27 Charlotte Wirl VP. Prevalence of asthma and allergies in children. European Environment and Health Information System Fact Sheet, World Health Organisation 2007; Fact Sheet No 3.1(May). 